\title{
TAXONOMY PROBLEMS OF VERBAL INFLUENCE TACTICS AND STRATEGIES Irina Akateva ${ }^{1}$, Lev Vasilev ${ }^{2}$, Ekaterina Oshanova ${ }^{3}$
}

\begin{abstract}
Human communication has been a relevant area of social research for last 50 years. It attracts the attention of psychologists, sociologists, culturologists, and, of course, linguists. The theory of verbal influence, which arose at the intersection of argumentation, rhetoric, and pragmatics, is now at the stage of forming its own terminological research vocabulary, as is evidenced by the lack of an elaborate system of tactics and strategies. The article highlights leading approaches to this problem within the framework of various scientific disciplines. It is worth mentioning that special contribution to the development of persuasion theory was made by marketers, by specialists in behavioral economics, by social psychologists and psychotherapists, that is, scholars and practitioners who did not study linguistic problems properly. The proposed conclusions make it possible to use theoretical achievements of related humanitarian disciplines to enrich the linguistic theory of persuasion.

UDC Classification: 81`42, DOI: https://doi.org/10.12955/pss.v1.34
\end{abstract}

Keywords: communication, verbal influence, compliance-gaining strategies, variable interpretation of reality.

\section{Introduction}

The art and science of effective communication or verbal influence has a relatively short history. It is an integral science that unites a whole complex of related disciplines, the subject of which is the efficiency of communication (Sternin, 2012). The problem of verbal influence remains relevant because a holistic model for the comprehensive study of existing knowledge of verbal influence principles has not been worked out so far.

The emergence of verbal influence science is a good example of the modern development of humanitarian scientific knowledge focused on the practical needs of modern society. That is the science of choosing the appropriate method of verbal influence on the person in a particular speech situation, of the ability to correctly combine different methods of speech influence depending on the roles of the participants of a communicative situation which helps to achieve the most productive results. Accordingly, one of the most important tasks to date, due to our increasing aspiration for the systematic study of the mechanisms of speech influence, remains the correct choice of strategies, tactics and techniques pertinent to achieving the communicative goal.

Based on the history of development, data, and methods of different sciences, it is believed that the basic affiliation of verbal influence is rhetoric, argumentation theory, and communicative linguistics. Therefore, the subject of the study of verbal influence is the process of effective communication. The demand for the study in question requires consideration of various sides of effective communication from the point of view of both theory and practical application.

\section{Verbal influence}

Verbal influence as an interdisciplinary scientific direction has several areas of actualization. First, we must consider the influence from the point of view of the specificity of human communication as its manifestation. Communication conditions are important to us, especially when it comes to the internal attitudes of its participants and their intentional component (communication objectives). "Communicative purpose and communicative intention work here as the basis for the formation of the communicative strategy and its tactics, respectively." (Kluev, 2002: 112). Based on the P. Grice's Cooperation Principle (Grice, 1975) and J. Leech's Politeness Principle (Leech 1983), cooperative and non-cooperative (conflict) strategies are considered as basic here (Issers, 2003). T.A. van Dijk and W. Kintsch W. write that there are different strategies for discourse production and comprehension: propositional strategies, local coherence strategies, textual and contextual macrostrategies, and schematic strategies (Dijk and Kintsch 1983).

In verbal influence, the scholar not only needs to see how at least one communication participant achieves his/her goals through planning and monitoring the communication process; it is no less

\footnotetext{
${ }^{1}$ Department of foreign languages, Izhevsk State Agricultural Academy, Izhevsk, Russian Federation, akatjewa@mail.ru

2 Department of linguistics and foreign languages, Tsiolkovsky Kaluga State University, Kaluga, Russian Federation, argumentation@mail.ru

${ }^{3}$ Department of Linguistics, Kalashnikov Izhevsk State Technical University, Izhevsk, Russian Federation, oshanova_katja@mail.ru
} 
important to understand what cognitive mechanisms of the recipient (object of influence) make it possible to achieve the above-mentioned goal. This means that the sphere of updating speech influence is directly related to the social and anthropological-psychological phenomena that guide communication participants in making decisions. The authors of the most influential classifications of influencing tactics and strategies are sociologists, social psychologists, behavioral economics specialists and educators (Kearney et al., 1984). Publications began to appear since the 1960s and they describe data obtained in experiments. We could have witnessed the expansion of the data from decade to decade, but the issue of the taxonomic descriptions of influence tactics and strategies was left unresolved. For example, G. Marwell and D.R. Schmitt wrote of 16 types of compliance-gaining techniques that they thought could be combined into 5 main clusters or classes:

- Rewarding activity

- Punishing activity

- Expertise

- Activation of impersonal commitments

- Activation of personal commitments (Marvel and Schmidt, 1967).

It has been common for the past 20 years to discuss in this area of science the problem of strategies, but without relating them to tactical content. There were 64 compliance-gaining strategies, according to Kathy Kellermann and Tim Cole (Kellermann and Cole, 1994). They noted the problem of atheoretical descriptions of persuasion strategy systems and noted that "conceptual definitions of the strategies are unclear, nonspecific, nonexclusive, and nondelimiting; these definitions make understanding the nature of the strategies difficult and classification unreliable".

Susan Weinschenk mentions 140 strategies, which are distributed among 7 motivators of behavior, the motivator of behavior being viewed as a sort of filter that helps to logically distribute all the strategies according to the sphere of use; however, in dialectical terms the filters also do not relate to the strategies in any way.

Finally, despite its social and psychological basis, speech influence is related to language. In the Russian-speaking linguistic community it is common to use the terms "speech strategies" and "speech tactics." Scholars working in the field of discourse of various types generally analyze the material of only one and very narrow sphere; they demonstrate that in different discourses there is almost an unlimited number of approaches to the formation of tactical-strategic systems of discourse construction. Only the principle of the ratio of strategies to tactics remains common; according to the former, the strategy is viewed as the attitude of the subject of influence to the achievement of his/her global goal in a given communicative event; tactics are regarded as the way to implement the plan. Thus the number of speech strategies and tactics is extremely broad, it is constantly enriched by the results of research in discoursology, in the theory of speech acts and genres, but the system of verbal influence tactics and strategies, obviously, has not yet been developed.

The fundamental premise for the existence of alternative verbal influence tactics and strategies is that there are competing language tools that can potentially describe the same situation. Studying people's motivation through the need for belonging G.M. Walton with colleagues found that the use of a noun instead of a single-headed verb demonstrates a stronger interest and a higher degree of attachment (Walton et al., 2012). Thus, respondents who used the "I 'am a chocolate eater" variant exhibited a stronger craving for chocolate than those who said "I eat chocolate a lot." A.N. Baranov calls this phenomenon a "variable interpretation of reality" and suggests a "fundamental mismatch between the structure of language as a discrete system and non-discrete reality" (Baranov, 2018: 177).

Thus, the provisions of the general semantics of A. Korzybski, who first stated that the description of an object is not that object ("map is not territory"), formed the basis of neurolinguistic programming (Dilts, 1999). The latter is now seen as one of the divisions of applied linguistics. Neurolinguistic programming was born out of observations by practicing psychologists and psychotherapists who tried to systematize and publicize the obtained facts. Now his techniques are used in various areas of human life. Robert Dilts thinks that the positive wording of the negative statement creates conditions for the emergence of a positive intention. The influenced person begins to perceive the problem in a different way (or frame). As a result of the reframing, the perception of some phenomenon as a problem becomes a setting for obtaining a positive result (Dilts, 1999). There is no discussion of strategies and tactics in neurolinguistic programming. It is only about techniques of influence, the essence of which is to change 
a person's belief about an object or a phenomenon, as well as to change his/her estimates or psychological attitude.

In addition, it should not be forgotten that there is an essential component in communication - oratory skills. The tandem of rhetoric and argumentation is meant to make a powerful impact on the audience. The task of the speaker is to make good use of the language tools that will help him implement the selected influence tactics.

\section{Conclusions}

Verbal influence theory has been actively developing for the last 40 years. The theory is interdisciplinary in nature. Related to the latter are the difficulties of solving taxonomic problems of the tactics and strategies terminology apparatus. It is accepted that the tactics and strategies approach came from the pragmatics of discourse into verbal impact theory, but chronologically many earlier systems of tactics and strategies were proposed within theories of social impact. Therefore, the starting points for the development of a system of reactive tactics and strategies, in our view, should be tactics and strategies of social impact, not communicative tactics and strategies.

\section{References}

Baranov, A.N. (2018) Lingvisticheskaya ekspertisa teksta [Linguistic examination of the text]. Ed. Flinta, 592 p.

Dilts, R. (1999) Sleight of Mouth. The Magic of Conversational Belief Change. Ed. Meta Publications. 330 p.

Dijk, T.A. Van, Kintsch W. Strategies of Discourse Comprehension. N.Y.: Academic Press, 1983. P. 153-211.

Grice, H.P. Logic and Conversation // Syntax and Semantics, Vol. 3. Speech Acts / Ed. by P. Cole and J.L. Morgan. - New York: Academic Press, 1975. - P. 41-58.

Issers, O. S. (2003) Kommunikativnye strategii i taktiki russkoi rechi [Communication strategies and tactics of Russian speech]. Ed. Editorial URRS. 248 p.

Kearney, P., Plax T.G., Richmond V.P., McCroskey J. C. (1984) Power in the Classroom IV: Alternatives to Discipline // Instructional Communication. P. 724-746.

Kellermann, K., Cole T. (1994) Classifying Compliance Gaining Messages: Taxonomic Disorder and Strategic Confusion. Communication Theory, Volume 4, Issue 1, February 1994, P. 3-60.

Kluev, E. V. (2002) Rechevaya kommunikatsiya [Speech communication]. Ed. Ripol klassik. 315 p.

Marwell, G. and Schmitt, D.R. (1967). Dimensions of compliance-gaining behavior: An empirical analysis. Sociometery, 30, P. 350-364.

Leech J. Principles of Pragmatics. - London etc.: Longman, 1983. - xii, 250 p.

Levine, T.R., Wheels, L.R. Situational intimacy as a predictor of compliance-gaining tactic selection // Communication Research Reports. 1997. I. P. 132-144.

Sternin, I.A. (2012) Osnovy rechevogo vosdeistviya [Bases of speech influence]. Ed. Istoki. 178 p.

Vasilev, L.G. (2016) Problema rechevogo vosdeistviya: otechestvennye i sarubezhnye podkhody [The Problem of Verbal Influence: Russian and Foreign Approaches]. Ed. Kaluga. 151 p.

Walton, G. M., Cohen, G. L., Cwir, D., \& Spencer, S. J. (2012). Mere belonging: The power of social connections. Journal of Personality and Social Psychology, 102(3), 513-532.

Weinschenk, S. (2013) How to Get People to Do Stuff: Master the art and science of persuasion and motivation. New Riders. $206 \mathrm{p}$. 